\title{
Are all prognostic factors in parotid gland carcinoma well recognized?
}

\author{
Dominik Stodulski • Boguslaw Mikaszewski • \\ Czeslaw Stankiewicz
}

Received: 25 February 2011 / Accepted: 12 July 2011 / Published online: 6 August 2011

(C) The Author(s) 2011. This article is published with open access at Springerlink.com

\begin{abstract}
The aim of his study was to assess the treatment results and prognostic factors in patients with parotid gland carcinoma. The material consisted of 109 patients treated surgically, with or without complementary radiotherapy, between 1978 and 2008 (follow-up at least 5-years). 5-year overall and disease-specific survival were observed in $57.0 \%$ of the patients and 5-year disease-free survival was achieved in $50.0 \%$. Univariate analysis including ten clinical and pathological features to assess their prognostic value was done. Parapharyngeal space invasion, facial nerve palsy, and high grade of tumor malignancy were the factors with the highest influence on the treatment results, because their presence decreased the chance for recovery 9.8, 9.7, and 8.2 times, respectively. Histologically positive cervical lymph nodes and extraparenchymal extension were the other factors connected with poor prognosis (prognosis worse 6.7 and 5.4 times, respectively). Clinically positive cervical lymph nodes, positive/uncertain microscopic margin, involvement of the deep lobe, or the whole gland increased the risk of treatment failure 3.4, 3.1, and 2.8, respectively. The age $\geq 60$ years and male gender were statistically significant factors, correlated with poor prognosis and decreased chance for recovery 2.4 and 2.6 times. T-status and clinical stage had important influence on 5-year disease-free survival rate because there were significant differences in the treatment results between individual stages. Multivariate analysis proved that the independent prognostic value, among anatomic structures involved by the neoplasm, had mandible, facial nerve, and skin infiltra-
\end{abstract}

D. Stodulski $(\bowtie) \cdot$ B. Mikaszewski · C. Stankiewicz Department of Otolaryngology, Medical University of Gdansk, ul. Debinki 7 (Klinika ORL), 80-211 Gdansk, Poland e-mail: dstodulski@gumed.edu.pl tion. Among tumor-related factors, T-stage and grade had the statistically significant influence on treatment results, and stage and lymph nodes metastases among clinical and pathological features. These results confirm the value of actually used TNM classification (2002). Although the parapharyngeal space invasion is a factor, which seems to have a significant, poor prognostic value, it was not included in this classification.

Keywords Parotid gland - Carcinoma · Prognostic factors · Treatment results $\cdot$ Parapharyngeal space invasion

\section{Introduction}

Parotid gland carcinoma is rare; it constitutes less than 3\% of all malignant head and neck tumors $[1,2]$. This is the reason why determining its prognostic factors basing on a large group of patients is very difficult or even impossible. Until now several factors have been recognized to have influence on prognosis and treatment outcome in patients with parotid carcinoma, and this made the TNM classification to evolve $[3,4]$. In actually used TNM classification (UICC 2002), T-stage is based on tumor size, presence of extraparenchymal extension, and anatomic structures invasion (Table 1) [5]. Despite its big clinical usefulness, it seems that this classification needs to be improved.

\section{Patients and methods}

The material consists of 109 patients treated for primary parotid carcinoma at Department of Otolaryngology of Medical University of Gdansk in the years 1978-2008, for whom the follow-up period was at least 5-years. Clinical staging 
of parotid carcinomas was based on TNM classification of UICC from 2002. Reclassification was done by verifying the patient data containing results of clinical, imaging (ultrasound, CT, MRI) and pathological examinations as well as surgical protocols. Histological reclassification was possible in 72 patients $(66 \%)$. Tumor grading was done based on original pathological reports or redone microscopic examination of the tumor.

The analyzed group consisted of 56 females $(51.4 \%)$ and 53 males $(48.6 \%)$. The patient age ranged from 11 to 90 years (median 58.6).

In the whole material the second (T2) and the fourth (T4) stage was predominating-35 (32.1\%) and $48(44.0 \%)$ patients, respectively. T1 stage was found in $11(10.1 \%)$ patients and T3 in 15 (13.8\%). Clinical assessment of cervical lymph nodes was done by palpation; in 78 patients it was followed by ultrasonography or computed tomography (CT). In 75 (68.8\%) patients the cervical lymph nodes were clinically N0. N1 and N2 stage was found in 20 (18.3\%) and $14(12.9 \%)$ patients, respectively. N3 stage was not observed in any case. There was a predominance of highgrade carcinomas-76 (69.7\%) cases, intermediate- and low-grade carcinomas were found in $8(7.3 \%)$ and 25 (22.9\%) patients, respectively. The most common carcinoma were as follows: adenocarcinoma (not other specified)-22 patients $(20.2 \%)$, carcinoma ex pleomorphic adenoma-21 patients (19.3\%), mucoepidermoid carcinoma-20 patients $(18.3 \%)$, and adenoid cystic carcinoma-18 patients $(16.5 \%)$. The remaining types: acinic cell carcinoma, undifferentiated carcinoma, squamous cell carcinoma, salivary duct carcinoma, sebaceous carcinoma, basal cell carcinoma, clear cell carcinoma, and papillary cystadenocarcinoma were found in 28 patients $(25.7 \%)$.

All patients underwent surgical treatment; 62 of them (56.9\%) had supplementary radiotherapy. In most patients treated with combined therapy, there was at least one indication for adjuvant radiotherapy. The complementary treatment was needed most frequently because of advanced tumor stage (T3/T4) and high-malignacy grade (59 and 60 patients, respectively) as well as the presence of metastases to regional lymph nodes (37 cases) and positive or uncertain surgical margins (29 patients).
Conservative parotidectomy (with the facial nerve preservation) was performed in 44 patients $(40.4 \%)$, semiconservative (with preservation of some facial nerve branches) - in 17 (15.6\%), and radical (with facial nerve sacrifice) in 48 patients $(44.0 \%)$. In 91 patients $(83.5 \%)$ the parotid surgery was associated with the neck dissection, it was mostly selective neck dissection of levels II, III, and V (67 patients-73.6\%), which was performed only in patients with clinically N0 neck. The remaining patients underwent radical or modified radical neck dissection.

In 37 of these patients (40.6\%) microscopic examination proved the presence of metastases in the regional lymph nodes and in 20 of them (30\%) the neck was assessed as N0. Nodal metastases were the most frequent in mucoepidermoid carcinoma, adenocarcinoma (not other specified), and carcinoma ex pleomorphic adenoma-52.4, 50.0, and $47.4 \%$, respectively. In the fourth frequent tumor-adenoid cystic carcinoma the cervical lymph nodes were involved only in $14.3 \%$ of patients. In the remaining tumors nodal metastases were remarkably present in salivary duct carcinoma (two out of three cases).

To assess the prognostic value of some selected clinical and pathological factors the univariate and multivariate analyses were done. The recovery criterion was 5-year disease-free survival.

The survival expectation was assessed by Kaplan-Meier method. To compare the survival expectation between the two groups of patients, a Wilcox test by Gehan was used. Multivariate analysis was done using Cox proportional hazard regression. The statistical significance level was established at $P<.05$. Assessing the prognostic factors, the odds ratio was used for measurement of strength of the effect.

\section{Results}

Treatment outcome

The overall survival (OS), disease-free survival (DFS), and disease-specific survival (DSS) were presented in Table 2 and Fig. 1. 10- and 15-year survivals are estimated values, as partly they are based on the censored observations.

Table 1 T stage of the major salivary glands

\begin{tabular}{ll}
\hline T1 & Tumor $2 \mathrm{~cm}$ or less in greatest dimension without extraparenchymal extension \\
T2 & Tumor more than $2 \mathrm{~cm}$ but not more than $4 \mathrm{~cm}$ in greatest dimension without extraparenchymal extension \\
T3 & Tumor more than $4 \mathrm{~cm}$ and/or tumor having extraparenchymal extension \\
T4a & Tumor invades skin, mandible, ear canal, or facial nerve \\
T4b & Tumor invades base of skull, pterygoid plates, or encases carotid artery \\
\hline
\end{tabular}

TNM classification (UICC 2002)

Extraparenchymal extension is clinical or macroscopic evidence of invasion of soft tissues or nerve, except these listed under T4a and T4b. Microscopic evidence alone does not constitute extraparenchymal extension for classification purposes 
Table 2 5-, 10-, 15-year overall survival, disease-specific survival, disease-free survival in patients with parotid gland carcinoma

\begin{tabular}{llll}
\hline & 5-year (\%) & 10-year (\%) & 15-year (\%) \\
\hline Overall survival & 57.0 & 34.0 & 24.0 \\
Disease-specific survival & 57.0 & 51.0 & 45.0 \\
Disease-free survival & 50.0 & 41.0 & 38.0 \\
\hline
\end{tabular}

In analyzed material of 109 patients, the 5-year DSS was $57.0 \%$, while 5-year DFS was $50.0 \%$.

Estimated value of 10- and 15-year DFS was 41.0 and $38.0 \%$, respectively.

The recurrence of disease was observed in 55 patients (50.5\%). The local recurrence was found in 18 cases (16.5\%). In 16 patients $(14.7 \%)$ the distant metastases were observed during the follow-up period, without signs of local or regional recurrence. In the following 17 cases the recurrence was multifocal (loco-regional recurrence- -5 cases, local recurrence and distant metastasis--4 cases, regional recurrence and distant metastasis--3 cases, loco-regional recurrence and distant metastasis- 5 cases). Isolated regional recurrence was found only in four cases (3.7\%). Nodal recurrence was observed in 17 patients: in $13(14.3 \%)$ of them after previously performed neck dissection, and in 4 (22.2\%) without neck treatment.

Most of recurrences (45 cases-81.8\%) were observed during the first 3 years of follow-up period.
Prognostic factors

\section{Univariate analysis}

Univariate analysis proved that the biggest influence on treatment results had the following factors: invasion of the parapharyngeal space and facial nerve paresis-nearly by ten times worsening the prognosis. Treatment results according to the presence of the parapharyngeal space invasion are presented at the Fig. 2. Poor prognosis was also associated with the high grade of tumor and the presence of nodal metastases, worsening the treatment outcome by 8.2 and 6.7 times, respectively. The remaining clinical and pathological factors, significantly worsening the prognosis (from 5.4 to 2.4 times) were extraparenchymal extension, clinically $\mathrm{N}+$ neck, uncertain/positive surgical margin, primary tumor location in the deep lobe or involving the whole parotid tissue, male gender, and the age $\geq 60$. These results are summarized in Table 3.

$\mathrm{T}$ stage had a significant influence on 5-year DFS, there were significant differences between the groups of patients with different $\mathrm{T}$ stages (T1-81.8\%, T2-74.3\%, T3$66.7 \%$, and $\mathrm{T} 4-18.7 \%$ ). T4 stage worsened the prognosis by 12.2 times compared with T1-T3 stage.

Similar differences in treatment outcomes were found between groups of patients with different clinical stage (I$88.9 \%$ ), II-73.3\%, III-73.2\% and IV-21.5\%). Patients with clinical stage I-III had 11.4 times better prognosis compared to patients with the IV stage. Univariate analysis
Fig. 1 Overall survival, disease-specific survival, diseasefree survival (diagonal lines on the survival curves indicate censored observations)

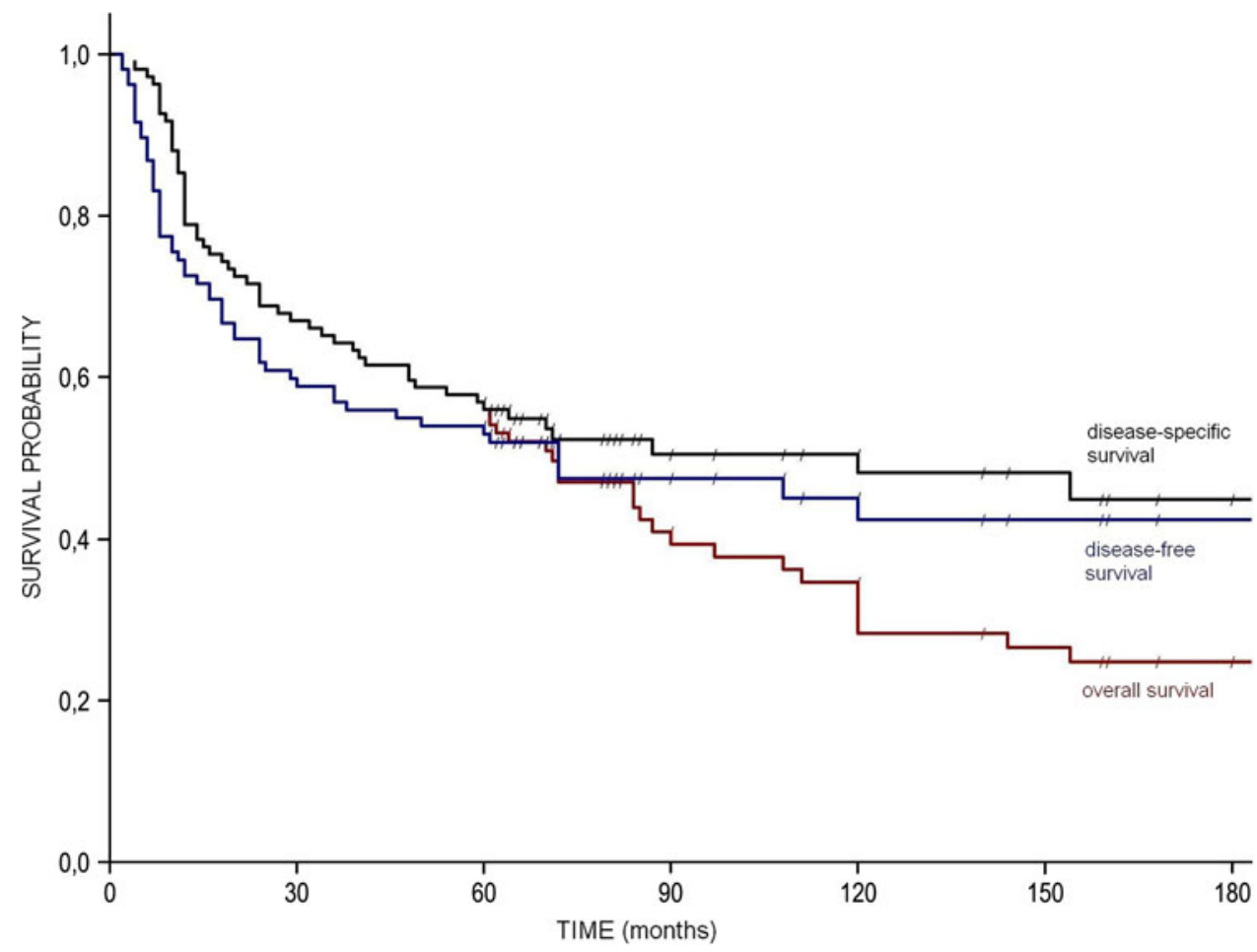


Fig. 2 Treatment results according to the presence of the parapharyngeal space invasion

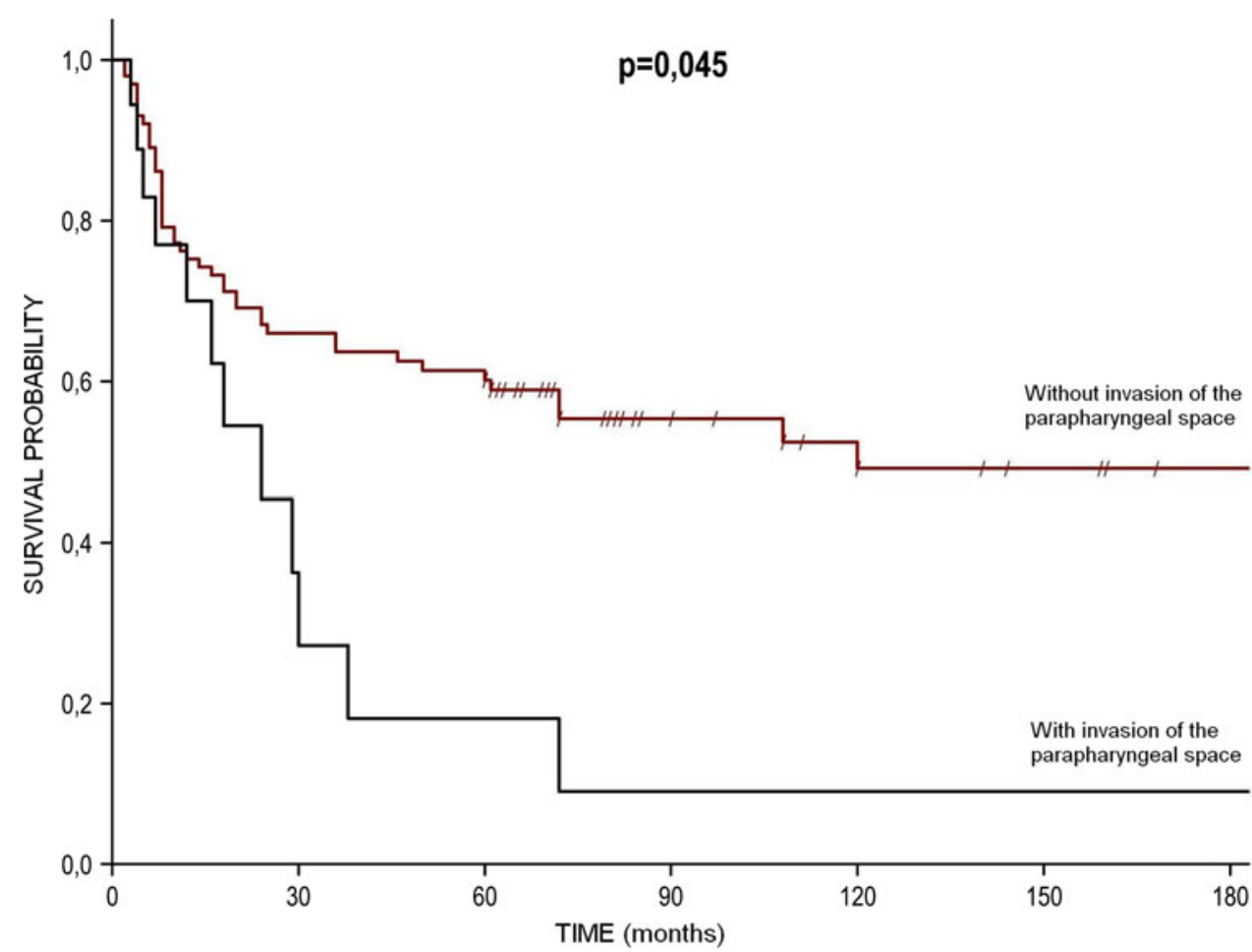

\begin{tabular}{lllll}
\hline & $\begin{array}{l}\text { 5-year disease-free } \\
\text { survival }(\%)\end{array}$ & $\begin{array}{l}\text { Odds } \\
\text { ratio }\end{array}$ & $\begin{array}{l}95 \% \text { confidence } \\
\text { interval }\end{array}$ & $P$ value \\
\hline Parapharyngeal space invasion & 11.8 & 9.8 & $2.1-45.1$ & 0.0007 \\
Facial nerve paresis/paralysis & 13.0 & 9.7 & $2.7-35.2$ & 0.0008 \\
High grade & 35.5 & 8.2 & $3.0-22.2$ & 0.0001 \\
Histologically positive cervical & 18.9 & 6.7 & $2.5-18.1$ & 0.0007 \\
$\quad$ lymph nodes & & & & \\
Extraparenchymal extension & 28.0 & 5.4 & $2.4-12.3$ & 0.0003 \\
Clinically positive cervical & 29.4 & 3.4 & $1.4-8.1$ & 0.005 \\
$\quad$ lymph nodes & & & & \\
Positive microscopic margin & 30.0 & 3.1 & $1.3-7.6$ & 0.012 \\
Deep lobe/whole gland & 38.3 & 2.8 & $1.3-6.0$ & 0.009 \\
Male gender & 37.7 & 2.6 & $1.2-5.5$ & 0.016 \\
Age ( $\geq 60$ years) & 38.9 & 2.4 & $1.1-5.1$ & 0.027 \\
\hline
\end{tabular}

Table 3 5-year disease-free survival according to selected clinical and pathological variables in univariate analysis proved the significant difference only between $\mathrm{T} 4$ patients compared with T1-T3 patients (T stage) and IV stage patients compared with I-III stage patients (clinical stage).

\section{Multivariate analysis}

Multivariate analysis of correlation between neoplastic infiltration of the anatomical structures and treatment outcome was performed (Table 4). The independent factors that had significant influence on 5-year DFS were infiltration of the mandible, facial nerve, and skin. Infiltration of the mandible increased the treatment failure by 4.13 times. Infiltration of the facial nerve and skin worsened the prognosis by 2.38 and 2.04 times, respectively. The remaining investigated factors proved to have no significant value in multivariate analysis.

Table 5 presents the multivariate analysis of the correlation of tumor-dependent parameters and treatment outcome. The independent significant factors for prognosis outcome proved to be the $\mathrm{T}$ stage and the tumor malignancy grade. The risk of treatment failure increased nearly twice with the each next $\mathrm{T}$ stage (1.78), whereas the tumor high grade increased it by 1.5 times. In the investigated multivariate analysis, $\mathrm{N}$ stage did not change significantly the treatment outcome. 
Table 4 Multivariate analysis

\begin{tabular}{llll}
\hline & $\begin{array}{l}\text { Hazard } \\
\text { ratio }\end{array}$ & $\begin{array}{l}\text { 95\% confidence } \\
\text { interval }\end{array}$ & $P$ value \\
\hline Mandible invasion & 4.13 & $1.22-13.92$ & 0.022 \\
Facial nerve invasion & 2.38 & $1.38-4.11$ & 0.002 \\
Skull base invasion & 2.25 & $0.45-11.26$ & 0.323 \\
Skin invasion & 2.04 & $1.04-4.00$ & 0.037 \\
$\begin{array}{l}\text { Parapharyngeal } \\
\quad \text { space invasion }\end{array}$ & 1.76 & $0.86-3.57$ & 0.120 \\
$\begin{array}{l}\text { Masseter muscle invasion } \\
\text { External auditory }\end{array}$ & 1.52 & $0.80-2.89$ & 0.202 \\
$\quad$ canal invasion & 1.06 & $0.40-2.79$ & 0.909 \\
\hline
\end{tabular}

Association of anatomical structures involved by the neoplasm with recovery

Table 5 Multivariate analysis

\begin{tabular}{llll}
\hline & Hazard ratio & $\begin{array}{l}\text { 95\% confidence } \\
\text { interval }\end{array}$ & $P$ value \\
\hline T stage & 1.78 & $1.29-2.45$ & 0.0005 \\
N stage & 1.48 & $0.84-2.61$ & 0.170 \\
Tumor grade & 1.47 & $1.12-1.92$ & 0.006 \\
\hline
\end{tabular}

Association of tumor related factors with recovery

Table 6 Multivariate analysis

\begin{tabular}{llll}
\hline & $\begin{array}{l}\text { Hazard } \\
\text { Ratio }\end{array}$ & $\begin{array}{l}\text { 95\% Confidence } \\
\text { Interval }\end{array}$ & $P$ Value \\
\hline Age $\geq 60$ years & 1.02 & $1.00-1.04$ & 0.018 \\
Male gender & 1.58 & $0.90-2.79$ & 0.114 \\
$\begin{array}{l}\text { Clinical stage } \\
\text { Histologically positive } \\
\quad \text { cervical lymph nodes }\end{array}$ & 1.82 & $1.26-2.62$ & 0.001 \\
$\begin{array}{c}\text { Positive/uncertain } \\
\text { microscopic margin }\end{array}$ & 1.06 & $1.26-4.14$ & 0.006 \\
\hline
\end{tabular}

$\overline{\text { Association of selected clinical and pathological variables with }}$ recovery

The correlation between clinical and pathological parameters and treatment outcome in multivariate analysis is presented in Table 6 . Independent significant prognostic factors were age, clinical stage and neck lymph nodes metastases. The risk of treatment failure increased by 1.02 times with each passing year. Each subsequent, higher clinical stage increased the risk of disease recurrence by 1.82 times, whereas the presence of nodal metastases increased it by 2.29 times. The remaining investigated factors did not have significant prognostic value.

\section{Discussion}

Despite a long period of time from which the analyzed material comes from, the principles for treating patients with malignant parotid gland tumors in our department were the same. Although in the 80s parotidectomies with the facial nerve sacrifice and radical neck dissections were performed more frequently, after 1990 began to prevail operations with preservation of all or part of the seventh nerve and the functional/selective neck dissections, which is consistent with the trend of preservative surgery in the past 30 years.

In published papers, 5-year DFS was higher than in our material (50.0\%) and ranged from 60 to 77\% [6-9]. According to literature, 5-year DSS of patients with parotid carcinoma was from 59 to $72 \%$ and OS, from 52 to $71 \%$ [6, 10-12]. In the material of Carrillo et al. 10-year OS and DFS were 74 and $60 \%$, respectively-these results are much better than ours [13]. The worse treatment results in our material might be explained by higher percentage of patients with III and IV clinical stage and high-grade carcinomas, and thus higher risk of locoregional recurrence and/ or distant metastases. It is interesting that during the 5-year follow-up all the deaths were associated with salivary gland cancer (OS was equal to DSS). However, during the 10and 15-year follow-up, the overall survival was far lower than those dependent on the disease ( 34 vs $51 \%$ and 24 vs $45 \%$ ) which was probably related to the age of treated patients and their concomitant diseases.

Predominance of high-grade carcinomas (clinically more aggressive ones) in our material had significant influence on clinical signs (high clinical stage) and treatment results. But this high proportion of patients (nearly $70 \%$ ) with highgrade carcinoma corresponds with the findings of other authors (from 41 to $73 \%$ ) [9, 10, 14, 15]. Worse results would be associated with the presence of undetectable (occult) distant metastases, as most of the patients before surgery had only routine radiograph of the chest. More careful diagnostic (bone scanning, abdominal ultrasound examination and CT scan of the thorax or brain) was performed from the breakthrough of the 80s and 90s and only in cases suspected for distant metastases. Nowadays, these examinations are performed in all patients with the high clinical stage (III and IV) when the patient is considered for surgical treatment.

In our opinion the extensive follow-up in order to detect distant metastases is not really necessary, as this has no effect on survival. It is much more important to control (palpations, ultrasound/CT) the tumor site and neck lymph nodes, and the early intervention in cases of loco-regional recurrences.

The authors support the necessity of postoperative radiotherapy (eventually combined with chemotherapy) in cases 
of low-differentiated/high-malignancy carcinomas, high clinical stage, nodal metastases, incomplete or close resection, and perineural or bone invasion, as according to literature it improved loco-regional control $[15,16]$.

Surprisingly high proportion of nodal metastases, especially occult, in our patients corresponds to that from literature (from 9 to 53\%), and in N0 cases from 9 to $48 \%$ of patients [8-11, 15, 17-22]. According to literature, the risk of nodal involvement in parotid carcinoma is related to its grade, microscopic structure (the highest in adenocarcinoma not other specified, mucoepidermoid carcinoma, undifferentiated, and squamous cell carcinoma), $\mathrm{T}$ stage (tumor size, facial nerve involvement, and extraparenchymal infiltration) [7, 12, 17, 19-22].

Our own experience and the results of other authors proved that neck dissection (elective or therapeutic) in parotid gland carcinoma should be performed, especially in cases with advanced $\mathrm{T}$ stage, high-grade tumors and when microscopic structure is related to the high risk of nodal metastases (when such information was obtained in the fine needle or frozen section biopsy). Since our paper was based on retrospective data, the analysis of metastatic nodes in individual neck levels was not possible. We think that in clinically N0 neck the elective neck dissection should cover levels II, III, and V, although in the material of Armstrong et al. the occult metastases involved also levels I and IV, which might suggest the need of radical modified neck dissection also in cases with unsuspicious cervical nodes [20].

The results of univariate analysis of the other authors confirm ours. According to literature, significant influence on 5-year survival had the following factors: age, male gender, facial nerve palsy, $\mathrm{T}$ stage, $\mathrm{N}$ stage, clinical stage, tumor grade, presence of nodal metastases, surgical margin, and extraparenchymal extension $[6-9,11-15,17,18,21$, 23]. Moreover, in many papers there are significant differences in treatment outcome related to histological structure of carcinoma [6, 11-13, 18, 21]. Witten et al. and Pedersen et al. $[8,19]$ proved that carcinoma ex pleomorphic adenoma had the worst prognosis. Due to the fact that definitely stronger influence on treatment outcome had the tumor malignancy grade than its microscopic structure, and because of large number of histological diagnoses (12 different types), and small number of some cases we did not conduct a similar analysis.

Pohar et al. [15] found in univariate analysis that perineural infiltration was a significant prognostic factor. In our material we found a particular bad prognosis in patients with T4 stage and IV clinical stage. In T4 patients ( $\mathrm{a}$ and $\mathrm{b}$ together), 10-year DFS was not observed in any patient, which confirms the prognostic value of infiltration of mentioned anatomic structures. In our results we did not observe a big difference; moreover, during the longer follow-up period, we found reversal of the survival curve, between T2 and T3 stages. Partly it could be explained by the fact that criterion for $\mathrm{T} 2$ and $\mathrm{T} 3$ is the tumor size $(\leq 4 \mathrm{~cm}>)$ and when tumor has the border size (around $4 \mathrm{~cm}$ ), the groups do not differ much.

Multivariate analyses presented by other authors proved to be significant the following prognostic factors: age, $\mathrm{T}$ stage, $\mathrm{N}$ stage, clinical stage, tumor grade, presence of nodal metastases, surgical margin, and extraparenchymal extension [7, 11, 12, 14, 15, 17, 18, 20, 21]. Terhaard et al. [23] showed that facial nerve paresis is an independent factor related to regional recurrence rate and DFS. Poorten et al. $[24,25]$ created four stages prognostic scale based on pre- and postoperative factors, such as age, pain, facial nerve function, $\mathrm{T}$ stage, $\mathrm{N}$ stage, clinical stage, surgical margin, skin, and perineural infiltration.

We did not find in the literature any analyses that would consider parapaharyngeal space invasion as poor prognostic factor, although in our univariate analysis it was remarkably worsening the prognosis. Multivariate analysis did not show a statistically significant effect of infiltration of this anatomical structure on the treatment outcome. However, it also did not confirm the prognostic significance of other well-known parameters-including infiltration of the skull base, which was related to their rare occurrence in this group of patients. The authors conclude that despite technical difficulties in performing radical surgery, parapharyngeal space invasion should be included into stage T4a of TNM classification of malignant tumors of the major salivary glands.

\section{Conclusions}

Our results proved that the facial nerve paresis/palsy and infiltration of the skin or mandible worsen the treatment results. This confirms the value of actually used TNM classification (2002). The parapharyngeal space invasion is a factor which was not included in this classification and which seems to have a significant, poor prognostic value. Among the nonanatomical factors, the high grade of malignancy of the tumor seems to have the greatest impact on treatment outcomes.

Open Access This article is distributed under the terms of the Creative Commons Attribution Noncommercial License which permits any noncommercial use, distribution, and reproduction in any medium, provided the original author(s) and source are credited.

\section{References}

1. Eneroth CM (1971) Salivary gland tumors in the parotid gland, submandibular gland, and the palate region. Cancer 27:1415-1418

2. Eveson JW, Cawson RA (1985) Salivary gland tumours. A review of 2410 cases with particular reference to histological types, site, age and sex distribution. J Pathol 146:51-58 
3. Carinci F, Farina A, Pelucchi S, Calearo C, Fini-Storchi O, Merlo R, Pastore A (2001) Parotid gland carcinoma: 1987 and 1997 UICC T classifications compared for prognostic accuracy at 5 years. Eur Arch Otorhinolaryngol 258:150-154

4. Numata T, Muto H, Shiba K, Nagata H, Terada N, Konno A (2000) Evaluation of the validity of the 1997 International Union against cancer TNM classification of major salivary gland carcinoma. Cancer 89:1664-1669

5. Sobin LH, Wittekind C (eds) (2002) Salivary glands. UICC TNM classification of malignant tumours, 6th edn. Wiley, New York, pp 48-51

6. Godballe C, Schultz JH, Krogdahl A, Møller-Grøntved A, Johansen J (2003) Parotid carcinoma: impact of clinical factors on prognosis in a histologically revised series. Laryngoscope 113:14111417

7. Leverstein $H$, van der Wal JE, Tiwari RM, Tobi $H$, van der Waal I, Mehta DM, Snow GB (1998) Malignant epithelial parotid gland tumours: analysis and results in 65 previously untreated patients. Br J Surg 85:1267-1272

8. Pedersen D, Overgaard J, Søgaard H, Elbrønd O, Overgaard M (1992) Malignant parotid tumors in 110 consecutive patients: treatment results and prognosis. Laryngoscope 102:1064-1069

9. Zbären P, Schüpbach J, Nuyens M, Stauffer E, Greiner R, Häusler R (2003) Carcinoma of the parotid gland. Am J Sur 186:57-62

10. Gallo O, Franchi A, Bottai GV, Fini-Storchi I, Tesi G, Boddi V (1997) Risk factors for distant metastases from carcinoma of the parotid gland. Cancer 80:844-851

11. Lima RA, Tavares MR, Dias FL, Kligerman J, Nascimento MF, Barbosa MM, Cernea CR, Soares JR, Santos IC, Salviano S (2005) Clinical prognostic factors in malignant parotid gland tumors. Otolaryngol Head Neck Surg 133:702-708

12. Theriault C, Fitzpatrick PJ (1986) Malignant parotid tumors. Prognostic factors and optimum treatment. Am J Clin Oncol 9:510-516

13. Carrillo JF, Vázquez R, Ramírez-Ortega MC, Cano A, Ochoa-Carrillo FJ, Oñate-Ocaña LF (2007) Multivariate prediction of the probability of recurrence in patients with carcinoma of the parotid gland. Cancer 15:2043-2051

14. Tullio A, Marchetti C, Sesenna E, Brusati R, Cocchi R, Eusebi V (2001) Treatment of carcinoma of the parotid gland: the results of a multicenter study. J Oral Maxillofac Surg 59:263-270
15. Pohar S, Gay H, Rosenbaum P, Klish D, Bogart J, Sagerman R, Hsu J, Kellman R (2005) Malignant parotid tumors: presentation, clinical/pathologic prognostic factors, and treatment outcomes. Int J Radiat Oncol Biol Phys 61:112-118

16. Terhaard CH, van der Schroeff MP, van Schie K, Eerenstein SE, Lubsen H, Kaanders JH, Smeele LE, Burlage FR, van Den Ende PL, Baatenburg de Jong RJ (2005) The role of radiotherapy in the treatment of malignant salivary gland tumors. Int J Radiat Oncol Biol Phys 61:103-111

17. Bell RB, Dierks EJ, Homer L, Potter BE (2005) Management and outcome of patients with malignant salivary gland tumors. J Oral Maxillofac Surg 63:917-928

18. Kelley DJ, Spiro RH (1996) Management of the neck in parotid carcinoma. Am J Surg 172:695-697

19. Witten J, Hybert F, Hansen HS (1990) Treatment of malignant tumors in the parotid glands. Cancer 65:2515-2520

20. Armstrong JG, Harrison LB, Thaler HT, Friedlander-Klar H, Fass DE, Zelefsky MJ, Shah JP, Strong EW, Spiro RH (1992) The indications for elective treatment of the neck in cancer of the major salivary glands. Cancer 69:615-619

21. Harbo G, Bundgaard T, Pedersen D, Søgaard H, Overgaard J (2002) Prognostic indicators for malignant tumours of the parotid gland. Clin Otolaryngol Allied Sci 27:512-516

22. Stennert E, Kisner D, Jungehuelsing M, Guntinas-Lichius O, Schröder U, Eckel HE, Klussmann JP (2003) High incidence of lymph node metastasis in major salivary gland cancer. Arch Otolaryngol Head Neck Surg 129:720-723

23. Terhaard C, Lubsen H, Tan B, Merkx T, van der Laan B, Baatenburg de Jong R, Manni H, Knegt P (2006) Facial nerve function in carcinoma of the parotid gland. Eur J Cancer 42:2744-50. Erratum in: Eur J Cancer, 2007, 43:1883

24. Poorten VV, Balm AJ, Hilgers FJ, Tan IB, Loftus-Coll BM, Keus RB, van Leeuwen FE, Hart AA (1999) The development of a prognostic score for patients with parotid carcinoma. Cancer 85:20572067

25. Poorten VV, Hart A, Vauterin T, Jeunen G, Schoenaers J, Hamoir M, Balm A, Stennert E, Guntinas-Lichius O, Delaere P (2009) Prognostic index for patients with parotid carcinoma: international external validation in a Belgian-German database. Cancer 115:540-550 